\title{
Development of a System to Calculate Energy Consumed by Diesel Railcars
}

\author{
Koichi MURAKAMI \\ Senior Researcher,
}

\author{
Ichiro HAGA
}

Senior Researcher,

\author{
Hideo NAKAMURA
}

Senior Researcher,

Drive Systems, Vehicle Control Technology Division

Shinichi MAEHASHI

Researcher,

Drive Systems, Vehicle Control Technology Division
Osamu YAMASHITA

Senior Researcher, Planning Systems, Transport Information Technology Division

The current situation surrounding global warming calls for strict countermeasures to address the issues involved. For instance, energy-saving measures based on methods of reducing energy consumption are required from railway operators. Accordingly, we have developed a new system that can calculate the amount of energy consumed by diesel railcars. The system uses software that enables the estimation of fuel consumption in train operation and the amount of carbon dioxide discharged in the process. This paper gives a summary of the system.

Keywords: environmental protection, energy saving, fuel consumption, train running curves, diesel railcars, diesel engines

\section{Introduction}

The situation surrounding environmental problems such as global warming caused by greenhouse gases and air pollution from exhaust gases calls for strict measures to address the issues involved. After the Kyoto Conference of 1997, rigorous regulations were demanded in the automotive and construction fields in many countries regarding fuel economy and exhaust emissions.

Against this background, Japan positively promotes environmental protection through stringent legislation. For instance, energy-saving measures based on methods of reducing energy consumption are required from railway operators running 300 vehicles or more $[1,2]$.

Table 1 shows briefly outlines of the actions undertaken by railway operators to save energy. These efforts consist of establishing energy-saving targets and programs, implementing effective train operation and introducing energy-saving vehicles.

In order to implement these actions, it has become increasingly necessary to quantitatively ascertain the amounts of energy used in train running. Accordingly, we have developed a new system that can calculate the amount of energy consumed by diesel railcars. The system consists of software that enables estimation of the volume of fuel consumed in train operation and the amount of carbon dioxide discharged in the process.

This paper gives a summary of the composition and

Table 1 Efforts by railway operators to save energy

Establishment of energy-saving targets and programs

Implementation of effective train operation

Introduction and promotion of the energy-saving vehicles

Reporting amounts of the energy consumed functions of the system.

\section{Summary of the calculation system}

Figure 1 shows the composition of the calculation system developed. It consists of a part that calculates train performance and another that calculates energy consumption.

The train-performance calculation system is based on software used for the development of regular running times, and enables the simulation of train running curves.

For this system, we use the SPEEDY train-performance calculation system previously developed by the Railway Technical Research Institute (RTRI) [3, 4]. This enables the output of data for train running curves as a text file in Comma Separated Value (CSV) format.

The system to calculate energy consumption, called DECOES, is based on software that enables the estimation of fuel consumption in mandatory train operation and the amount of carbon dioxide $\left(\mathrm{CO}_{2}\right)$ emitted using data from SPEEDY. The DECOES system allows various calculations based on the methodology outlined below.

First, the system reads train running curve data, engine load data and engine performance data for calculation. Secondly, using engine load data showing the train speed and engine speed, it finds the engine driving point (engine speed point) in train running. Thirdly, using engine performance data showing the characteristics of fuel consumption, DECOES obtains the rate of fuel consumption per hour (instantaneous fuel consumption) at the engine driving point. Finally, the system calculates the volume of fuel consumption from the instantaneous fuel consumption and the engine driving time.

Using a similar technique, DECOES can calculate the amount of carbon dioxide emitted using engine performance data that shows the characteristics of carbon 


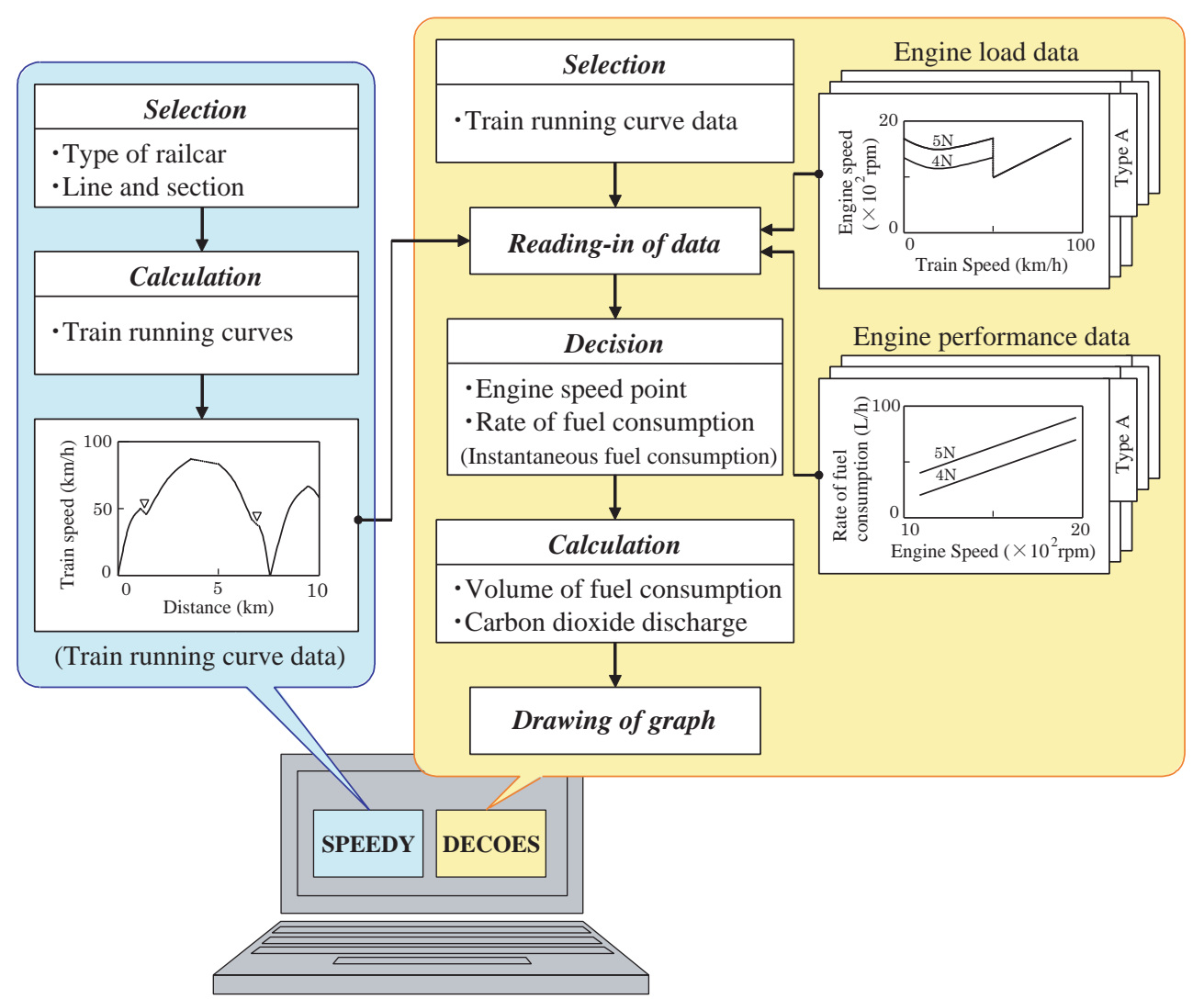

Fig. 1 Composition of the calculation system

dioxide emission.

\section{Scope of the calculation system}

This chapter describes the scope (in terms of factors such as operability and functionality) of the DECOES system that calculates energy consumed by diesel railcars from train running curve data.

We produced the operation display and a calculation practice part using the $\mathrm{C} \#$ programming language, and the display part of the calculation results was established using Microsoft Excel 2003.

\subsection{Operability of DECOES}

The operation display of DECOES is shown in Fig. 2 . The system can be easily operated through this display by the following three steps:

Step 1: In Selection of running curve data in the upper part of the operation display, select the data file of the running curves for the calculation object. We can see the primary calculation condition for this data in the central part of the display, enabling confirmation that this is the running curve data expected.

Step 2: In Selection of engine data in the lower part of the operation display, select the files of the engine load/engine performance data for the running curve data.

Clicking the reference button shows a list of these data files on the display, and object files can be selected

\section{System to calculate energy consumed ver1.01 $\quad-$ 回 $x$}

\begin{tabular}{|c|c|c|}
\hline ¥Decoes¥Input data¥ & ÆTrain running curve ¥KIHA40.csv & Reference \\
\hline \multicolumn{3}{|c|}{ Calculation conditions } \\
\hline -Car type: & KIHA40 & \\
\hline - Car weight: & $38.5 \mathrm{t}$ & \\
\hline -Engine type: & DMF15HSA & \\
\hline - Car occupacy: & $100 \%$ & \\
\hline - Line and Section: & Koutoku Takamatsu-Sanbonmatsu & \\
\hline -Distance: & $37.650 \mathrm{~km}$ & \\
\hline
\end{tabular}

- Selection of engine data
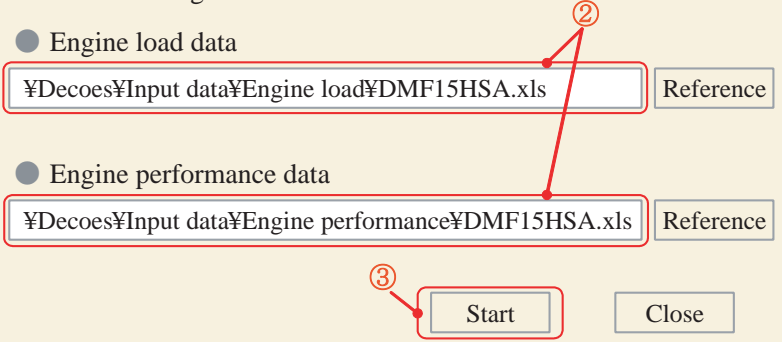

Close

Fig. 2 DECOES operation display

from the list.

Step 3: Clicking the Start button in the lower part of the operation display causes the system to execute 
calculation, and the results are displayed immediately.

We can produce results of calculation as shown in Fig. 3 with these very simple, easy operation steps

\subsection{Function of DECOES}

The DECOES system has a function to display the results of calculation and draw graphs to show changes in fuel consumption over time.

First, a display example of the calculation results is shown in Fig. 3. In the upper part of this display, the primary calculation conditions such as car type, engine type or line and section are indicated. In the central part, analysis of running conditions such as powering, coasting and braking is shown. In the lower part, the volume of fuel consumption, carbon dioxide discharge and running mileage are indicated.

In addition, this system enables calculation of the amounts of carbon monoxide ( $\mathrm{CO}$ ) and nitrogen oxide (NOx) emitted in exhaust gases.

An example of a calculation results graph is shown in Fig. 4. In the upper part of the graph, the running conditions and notch positions in train running are indicated. In the central part, the train speed and engine speed of the train are shown. In the lower part, the rate of fuel consumption and the volume of fuel consumed on the train are indicated.

Using these functions, the environmental performance of diesel railcars (such as the value of fuel consumption or carbon dioxide discharge) and changes in performance with running distance can be quantitatively and accurately ascertained.

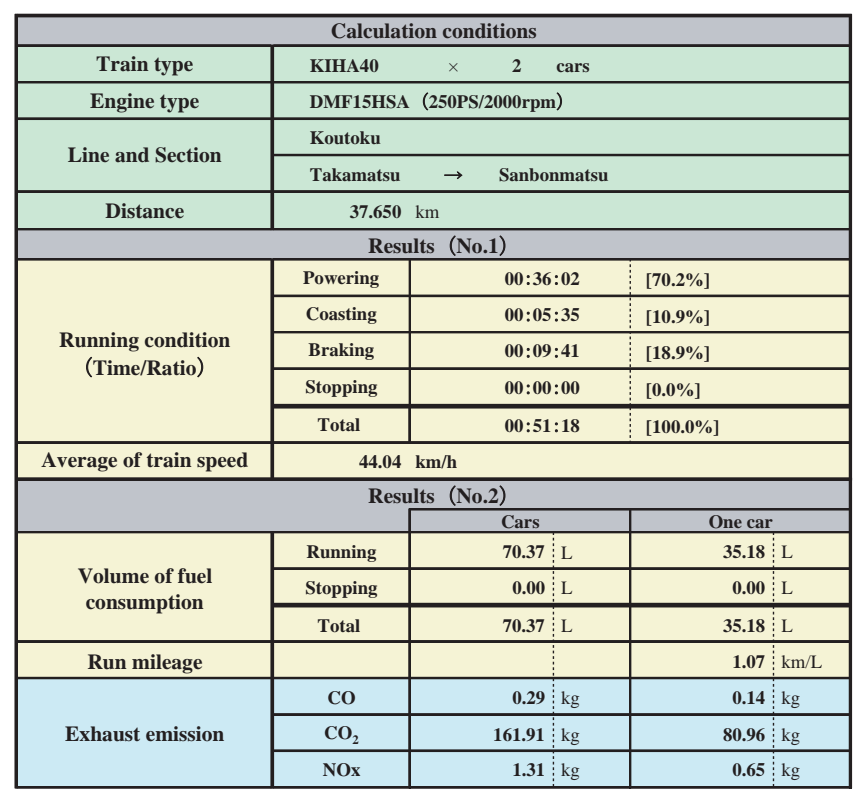

Fig. 3 Results of calculation

\section{Evaluation of calculation precision}

We measured the volume of fuel consumption in a running test and compared the measured and calculated values to verify the validity of the calculation system.

This chapter gives a summary of this running test and the results of comparing the two sets of values.

\subsection{Running test}

In July 2008, we conducted a running test on Japan's
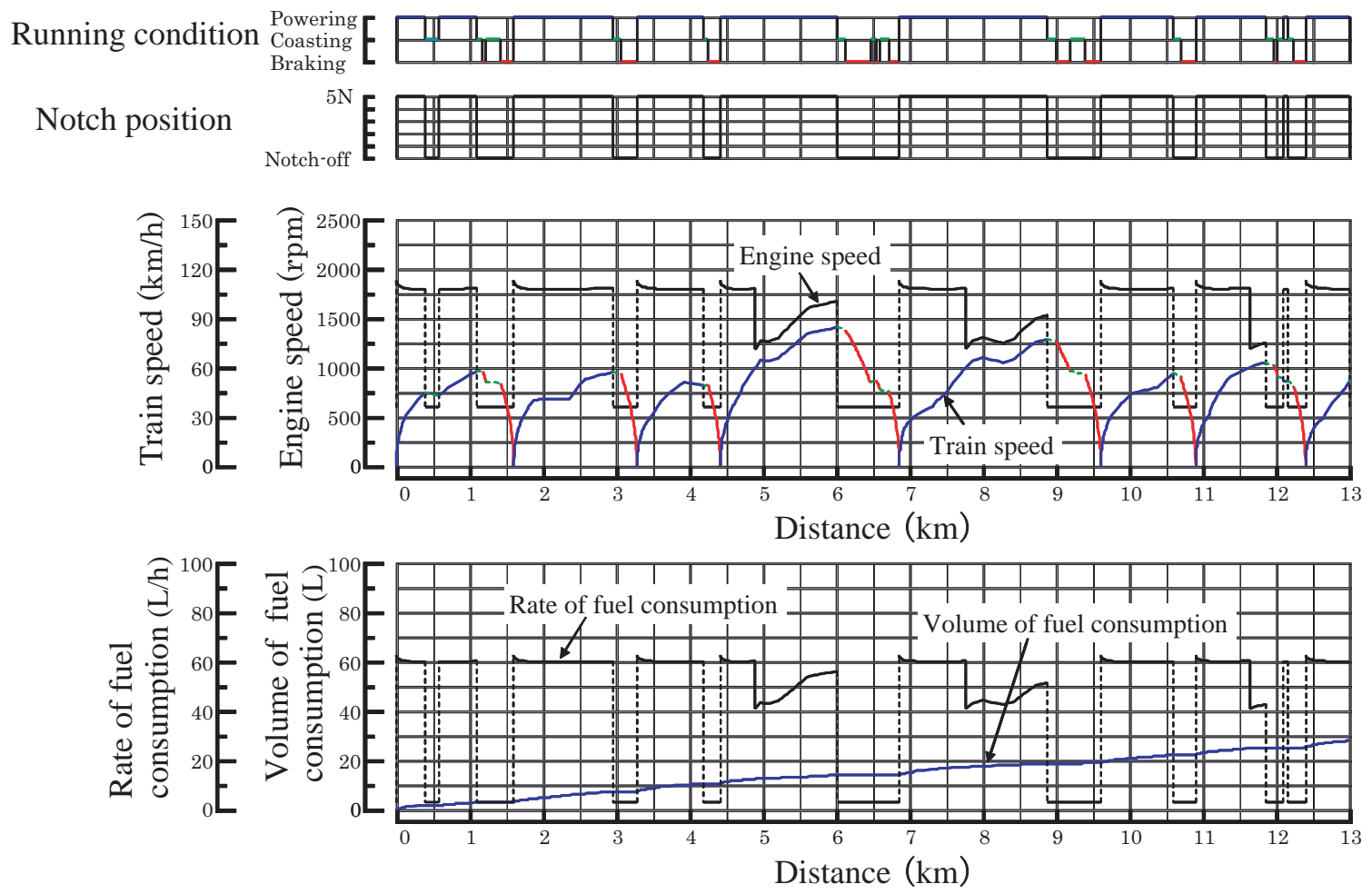

Fig. 4 Display example of graph drawn 
Koutoku Line with the cooperation of the Shikoku Railway Company (JR Shikoku). This line is a main section covering a distance of $78.05 \mathrm{~km}$ and linking the areas of Takamatsu and Tokushima.

The appearance of the diesel railcar used in this running test is shown in Fig. 5 (a). The railcar is a KIHA47

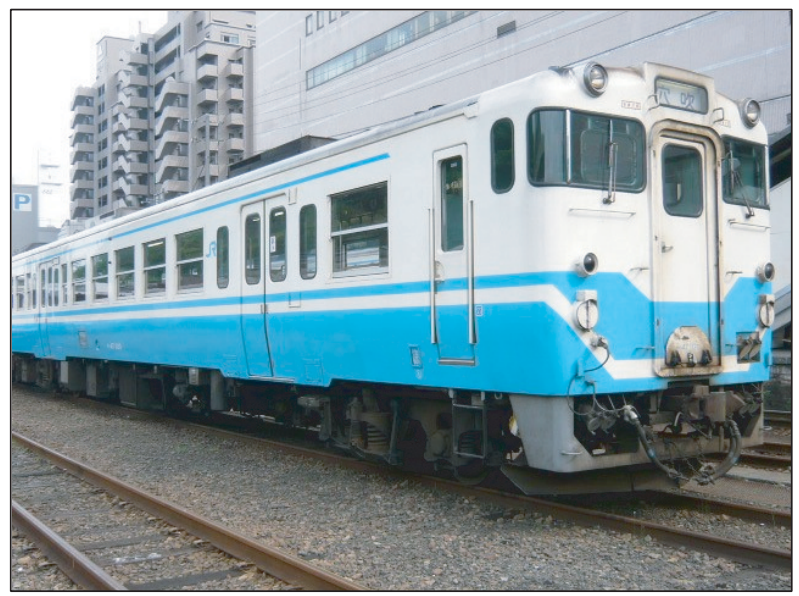

(a) Appearance of the railcar

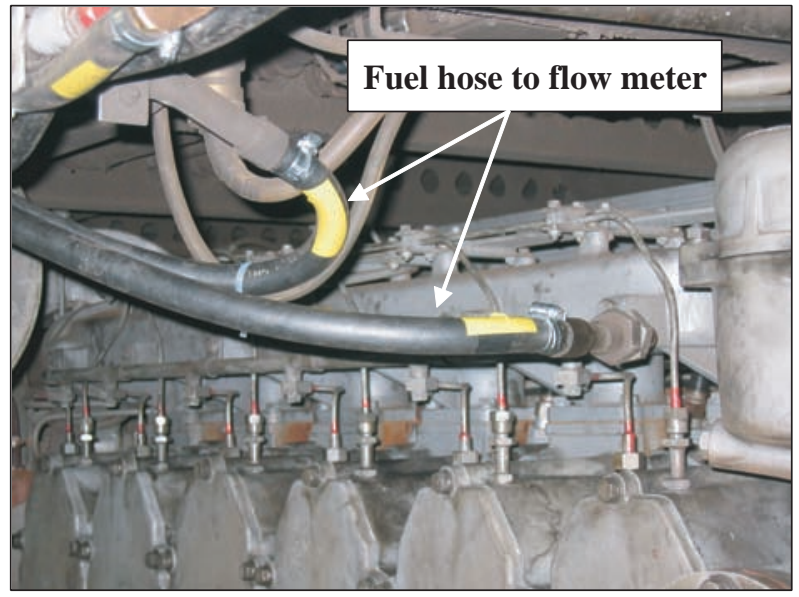

(c) Setting situation of the flow meter

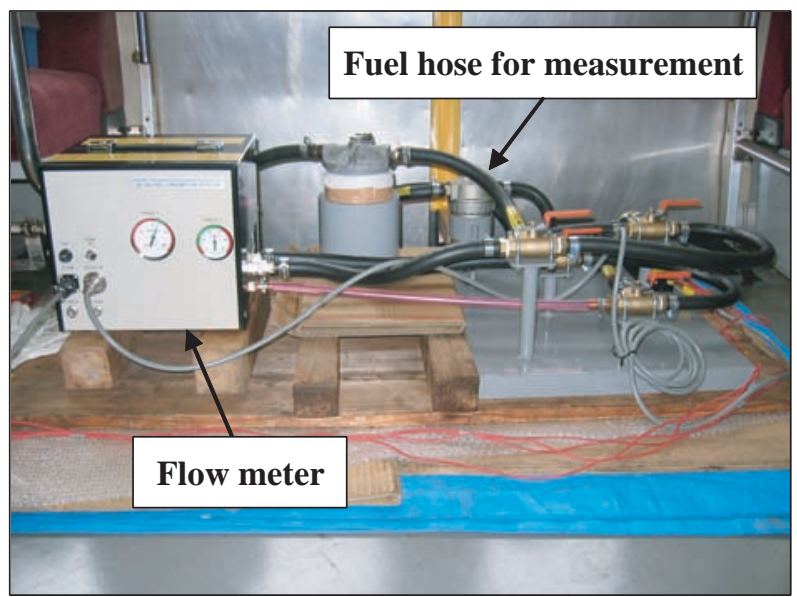

(c) Setting situation of the flow meter

Fig. 5 Running test on a diesel railcar series with a weight of approximately $36.0 \mathrm{t}$, and is equipped with a $184 \mathrm{~kW}$ (250 PS/2,000 rpm) six-cylinder diesel engine and a two-step shift transmission.

During the running test, we measured the volume of fuel consumption using a flow meter installed on the railcar as shown in Fig. 5 (c).

\subsection{Comparison of measured and calculated values}

For a case where the railcar ran between SanukiTsuda and Kanzaki, a comparison of the measured and calculated values is shown in Table 2 . In addition, a comparison of the running curves is shown in Fig. 6.

In this case, most of the calculated values over the running time were the same as the measured values, and the running curves were also almost identical. The measured volume of fuel consumption was $2.50 \mathrm{~L}$, while the calculation system produced a value of $2.70 \mathrm{~L}$. At other station intervals, the difference in the measured and calculated values was in the range of approximately $\pm 0.20 \mathrm{~L}$.

These comparison results therefore confirm that the calculation system has sufficient validity.

Table 2 Measured and calculated values

\begin{tabular}{c|c|c|c}
\hline \multicolumn{2}{l|}{} & Measured values & Calculated values \\
\hline \multicolumn{2}{c|}{ Driving time (min:sec) } & $5: 05$ & $5: 06$ \\
\hline $\begin{array}{c}\text { Running condition } \\
\text { (min:sec) }\end{array}$ & Powering & $3: 15$ & $3: 00$ \\
\cline { 2 - 4 } & Coasting, braking & $1: 50$ & $2: 06$ \\
\hline Volume of fuel consumption (L) & 2.50 & 2.70 \\
\hline
\end{tabular}

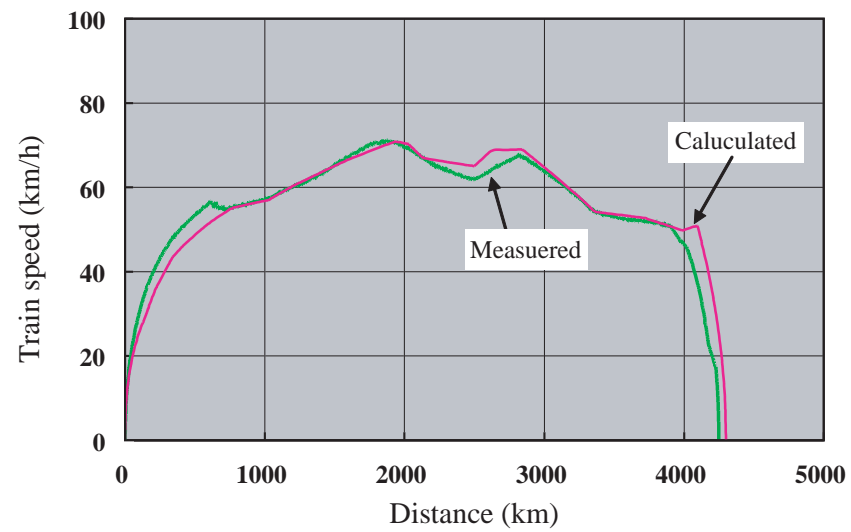

Fig. 6 Running curves

\section{Conclusion}

The trend of energy saving prompted by the issue of global warming is spreading through the fields of railroads, construction and aviation. Against this background, we have developed a new system that can calculate the energy consumed by diesel railcars.

Using this system, we can quantitatively ascertain the volume of fuel consumed in train running, and the results can be used to discuss energy-saving measures including the reduction of fuel consumption. 
We plan to extend this system to support efforts toward further energy savings in the future.

\section{References}

[1] Murakami, K., Haga, I. and Yamashita, O., "An Environmental Evaluation System for Diesel Railcars," $R R R$ Report, pp. 22 - 24, August 2007 (in Japanese).

[2] Murakami, K., Haga, I., Yamashita, O. and
Nakamura, H., "An Energy Calculation System for Diesel Railcars," RTRI Report, Vol. 21, No. 7, pp. 39 40, 2007 (in Japanese).

[3] Hirano, J., Tomii, N. and Yamashita, O., "Development of A Train Performance Calculation System," RRR Report, pp. 9 - 14, May 1992 (in Japanese).

[4] Hirano, J., Tomii, N. and Yamashita, O., "Development of A Train Performance Calculation System on an Engineering Workstation," Computers in Railways III, Vol. 1: Management, pp. 127 - 136, 1992. 